\title{
Applying theory of planned behavior to predict exercise maintenance in sarcopenic elderly
}

\author{
This article was published in the following Dove Press journal: \\ Clinical Interventions in Aging \\ 16 September 2014 \\ Number of times this article has been viewed
}

\author{
Mohamad Hasnan Ahmad' \\ Suzana Shahar ${ }^{2}$ \\ Nur Islami Mohd \\ Fahmi Teng ${ }^{2}$ \\ Zahara Abdul Manaf ${ }^{2}$ \\ Noor Ibrahim Mohd Sakian ${ }^{3}$ \\ Baharudin Omar ${ }^{4}$ \\ 'Centre of Nutrition Epidemiology \\ Research, Institute of Public Health, \\ Ministry of Health, Kuala Lumpur, \\ Malaysia; ${ }^{2}$ Dietetics Program, \\ ${ }^{3}$ Occupational Therapy Program, \\ ${ }^{4}$ Department of Biomedical Sciences, \\ Faculty of Health Sciences, Universiti \\ Kebangsaan Malaysia, Kuala Lumpur, \\ Malaysia
}

\begin{abstract}
This study aimed to determine the factors associated with exercise behavior based on the theory of planned behavior (TPB) among the sarcopenic elderly people in Cheras, Kuala Lumpur. A total of 65 subjects with mean ages of $67.5 \pm 5.2$ (men) and $66.1 \pm 5.1$ (women) years participated in this study. Subjects were divided into two groups: 1 ) exercise group ( $n=34 ; 25$ men, nine women); and 2 ) the control group ( $n=31 ; 22$ men, nine women). Structural equation modeling, based on TPB components, was applied to determine specific factors that most contribute to and predict actual behavior toward exercise. Based on the TPB's model, attitude $(\beta=0.60)$ and perceived behavioral control $(\beta=0.24)$ were the major predictors of intention to exercise among men at the baseline. Among women, the subjective norm $(\beta=0.82)$ was the major predictor of intention to perform the exercise at the baseline. After 12 weeks, attitude (men's, $\beta=0.68$; women's, $\beta=0.24$ ) and subjective norm (men's, $\beta=0.12$; women's, $\beta=0.87$ ) were the predictors of the intention to perform the exercise. "Feels healthier with exercise" was the specific factor to improve the intention to perform and to maintain exercise behavior in men $(\beta=0.36)$ and women $(\beta=0.49)$. "Not motivated to perform exercise" was the main barrier among men's intention to exercise. The intention to perform the exercise was able to predict actual behavior regarding exercise at the baseline and at 12 weeks of an intervention program. As a conclusion, TPB is a useful model to determine and to predict maintenance of exercise in the sarcopenic elderly.

Keywords: theory planned behavior, aging, elderly, sarcopenic, exercise
\end{abstract}

\section{Introduction}

Many theories abound that seek to explain the developmental changes in human behavior over the course of a life. These theories try to explain, through the conceptions and mechanisms of factors, how humans intend to behave in intentional or unintentional manners. The theory of social learning, ${ }^{1}$ the social learning and Piaget's cognitive theory, ${ }^{2}$ the theory of reasoned action, ${ }^{3}$ and the theory of interpersonal behavior ${ }^{4}$ are examples of theories that have been applied to the investigation of the behavioral changes in individuals over the years. However, some of the theories are rather complex to understand, and some do not cover all the factors that influence human behaviors.

In 1985, Ajzen ${ }^{7}$ proposed the theory of planned behavior (TPB) to explain briefly and concisely how humans were perceived to perform various behaviors under the influence of intention. According to the TPB, intention is the immediate antecedent and perceived behavioral control is an additional factor that differs from the theory of reasoned action. ${ }^{5}$

TPB clearly proposes a model about how human action is guided so it can be used to predict the occurrence of a specific behavior by linking four specific components. These four components are: 1) attitude toward behavior; 2) subjective norms; 3) perceived behavioral control; and 4) intention..$^{5-7}$ Figure 1 represents the conceptual framework of TPB.
Correspondence: Suzana Shahar Dietetics Program, Faculty of Health Sciences, Universiti Kebangsaan Malaysia, Jalan Raja Muda Abdul Aziz, 50300 Kuala Lumpur, Malaysia

Tel +60 392897667

Fax +60 326947621

Email suzana.shahar@gmail.com 


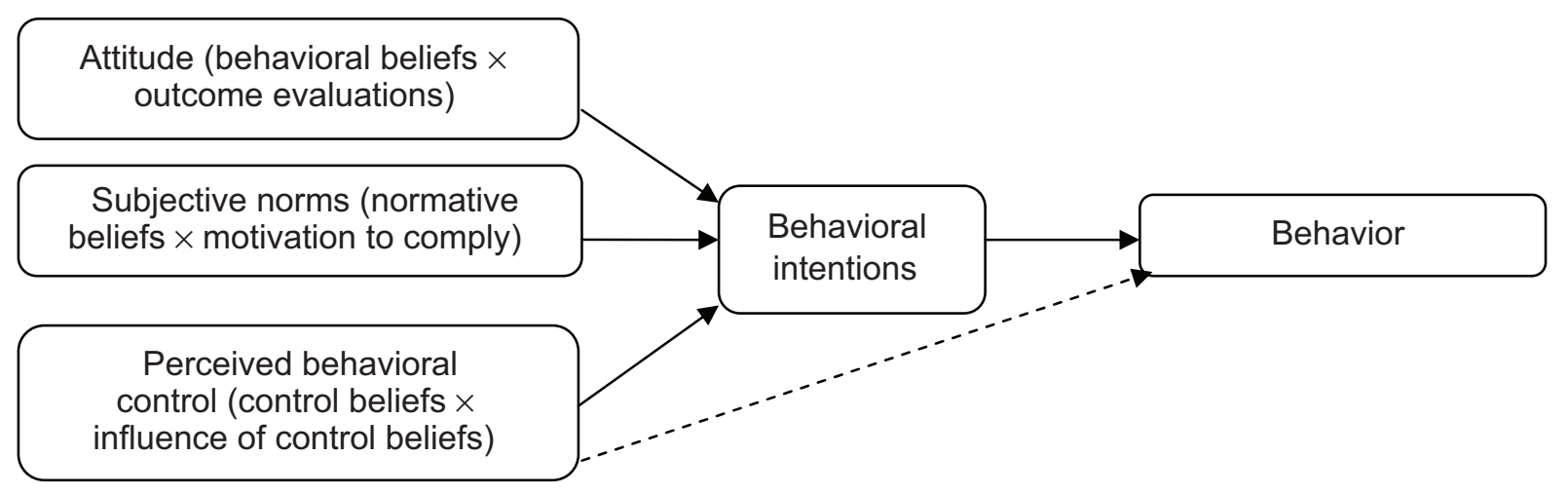

Figure I Conceptual framework of theory of planned behavior.

Note: Data from Ajzen I. The theory of planned behaviour: reactions and reflections. Psychol Health. 20 I I;26(9): I I I3-I I 27. ${ }^{7}$

Intention is the precursor of behavior, since it is an intermediate component between the other three components to the actual behavior. ${ }^{5,7,8}$ According to the theory of reasoned action (TRA), the behavior taken by an individual must be intentional. The attitude toward behavior and the subjective norm are the components that contribute to this intention. However, later study reveals that intention can only accurately predict behavior when the behavior is under the individual's volitional control. Therefore, Ajzen (1985) added perceived behavioral control in the TRA, which included influence of an individual's volitional control and named the new model as TPB. ${ }^{7}$

Thus, intention is determined by three conceptually independent variables: 1) labeled attitude; 2) subjective norm; and 3) perceived behavioral control. Generally, the more favorable the attitude and subjective the norm, and the greater the perceived behavioral control, the stronger should be the individual's intention to perform a particular behavior. ${ }^{9}$

Attitude toward the behavior is defined as the person's overall evaluation of the behavior. It emphasizes two subcomponents, which are behavioral beliefs (beliefs about the consequences of the behavior) and outcome evaluation (corresponding negative or positive judgments about each of these features of the behavior). Subjective norms are a person's own estimate of the social pressure to perform, or not perform, the target behavior.

Subjective norms also have two subcomponents, which include normative beliefs (beliefs about the assumptions that other people or someone important make about certain behavior) and motivation to comply (positive or negative judgments about each belief). Perceived behavioral control of the behavior is the extent to which a person feels able to enact the behavior. It has two aspects, which are how much a person has control over the behavior and how confident a person feels about being able to perform, or not perform, the behavior. It is determined by control beliefs about the power of both situational and internal factors to inhibit or facilitate the performing of the behavior. Therefore, perceived behavioral control is the only component that has direct interaction to intention and actual behavior. ${ }^{7,8}$

Low physical activity level will increase the risk to noncommunicable diseases, such as obesity, diabetes, and stroke. ${ }^{10,11}$ With the onset of aging, muscle mass and strength will gradually decline - a condition referred to as sarcopenia. A lack of a resistance type of exercise is documented as one of the risk factors for this syndrome. ${ }^{12}$ Elderly with sarcopenia tend to have limited functional ability and poor quality of life. ${ }^{13,14}$ However, sarcopenia can be reversed and treated by the appropriate intervention. Exercise and nutrition are among the most effective interventions to combat sarcopenia. ${ }^{15,16}$ However, the practicality of exercise in the elderly is questionable because there are physical, mental, and demographic barriers that this population may face. The TPB is widely applied to facilitate understanding toward a number of health behaviors. Therefore, the aim of this study is to explore the obstacles and barriers that the sarcopenic elderly face when they are asked to perform regular exercise and to predict the maintenance of exercise behavior among them through focus group discussion based on TPB components. It is expected that TPB will provide a systematic and comprehensive framework that allows the assessment of the personal, social, and psychological effects on the individual's exercise intention through the investigated variables.

\section{Methodology Study design and subjects}

Prior to the actual study, eleven subjects (three men and eight women) were randomly selected from a senior citizen's club in Cheras, Kuala Lumpur, for a focus group 
discussion (FGD). This FGD aimed to discuss factors that influence exercise behavior among older people. Responses from the subjects were listed and grouped, according to four different components of TPB. Then, a set of questionnaires for assessing exercise behavior was developed, based on the TPB components. The reliability test indicates a good Cronbach's alpha value, ie, $0.69,0.75,0.55$, and 0.91 for attitude, subjective norm, perceived behavioral control, and intention, respectively.

A quasi-experimental trial was conducted from FebruaryMay 2010 among 76 elderly people (56, men; 20, women) aged 60-75 years old. Subjects were recruited from four senior citizen clubs, namely Sri Labuan, Sri Sabah, Jalan Siakap, and Desa Tun Razak in Cheras, Kuala Lumpur. They were divided into an exercise group (ExG; $n=34$; Sri Sabah and Desa Tun Razak) and a control group (CoG; $n=31$; Sri Labuan and Jalan Siakap). Inclusion criteria were sarcopenic elderly aged 60-75 years old, permanent resident for at least 1 year, had no terminal illness, and no mental illness. Those with chronic diseases and who were physically dependent were also excluded. Subjects were grouped according to their housing area to increase compliance to the prescription exercise and to avoid a cross-contaminated intervention effect between ExG and CoG. Subjects in the ExG were provided with a TheraBand ${ }^{\circledR}$ (The Hygienic Corporation, Akron, OH, USA), which is an elastic band that may be used to assist in performing resistance exercise.

Participants were asked to perform this exercise program three times per week for 12 weeks, including two times per week with assistance from certified trainers with a sports science and physiology background. Throughout the 12 weeks, Mondays and Wednesdays were allocated for exercise programs at Sri Labuan; the exercise programs were on Tuesday and Thursday for subjects in Jalan Siakap. Attendance for exercise sessions was taken, and exercise diaries were provided to monitor compliance toward exercise programs. Videos and booklets on exercise, as shown in Figure 2, were provided as guidelines for the subjects. The guideline was a well-rounded exercise program developed partly from the TheraBand ${ }^{\circledR}$ resistance training instruction by TheraBand ${ }^{\mathbb{R}}$ Academy. ${ }^{17}$

\section{Measurements}

Sociodemographic data, socioeconomic status, anthropometric characteristics, and health status were obtained at baseline using a pretested questionnaire. Anthropometric parameters being measured were: body weight (TANITA lithium digital scale HD-319; TANITA Corporation, Tokyo,

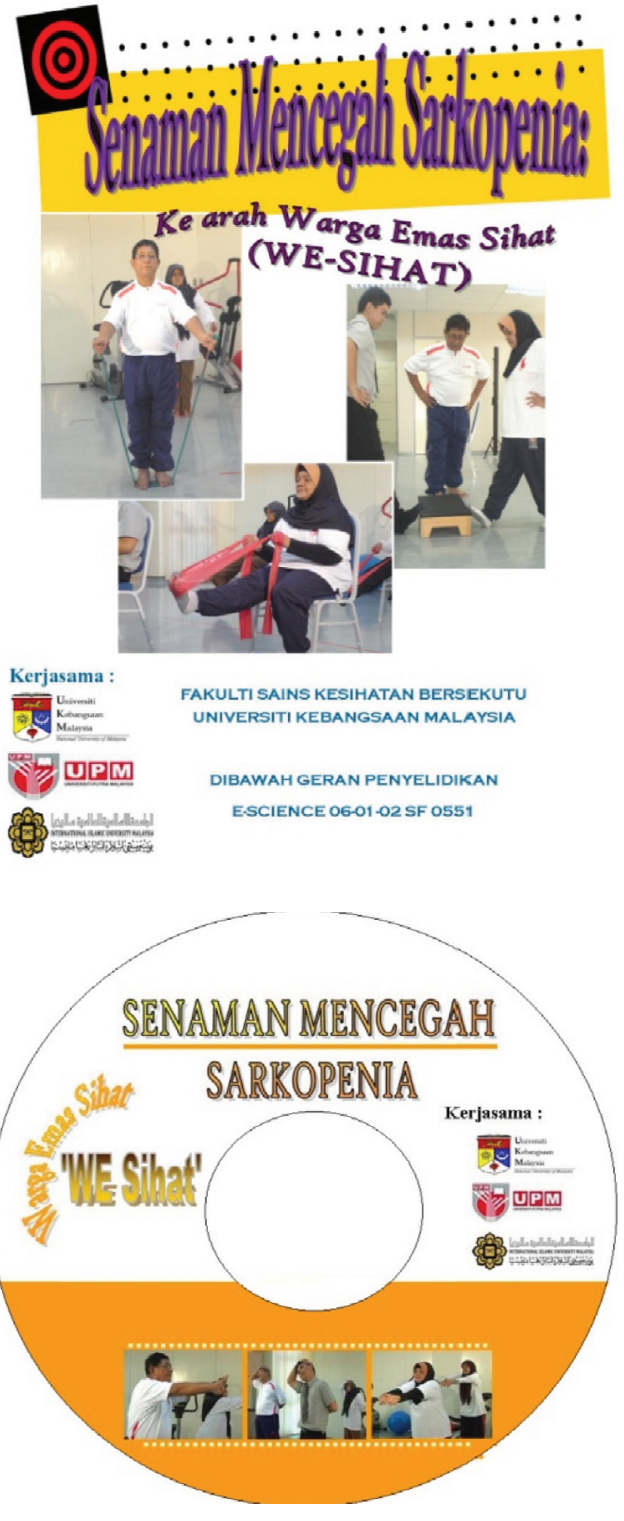

Figure 2 Video and booklet guidelines given to the subject.

Japan); height (Seca Leicester Portable Height Measure; Seca GmbH \& Co KG, Hamburg, Germany); and waist and mid upper arm circumference (Seca Measuring Tape; Seca GmbH \& Co KG). Handgrip strength was also measured by using a hydraulic hand dynamometer (Sammons JAMAR 7498-05 Hydraulic Hand Dynamometer; Sammons Preston Rolyan, Chicago, IL, USA). The similarity in demographic, economic, anthropometry characteristics, and health status between subject groups was important to avoid bias, as these variables significantly influence individual behavior. Subjects were interviewed individually to obtain data on attitude, subjective norm, perceived behavioral control, and intention of actual behavior using the questionnaire that was created from the FGD. Actual behavior was measured using 
an international physical activity questionnaire at baseline and 12 weeks of intervention study. The international physical activity questionnaire provided total metabolic equivalence value to estimate the participation of the subject in physical activity behavior.

Each component in TPB was transformed into variables to make it analytically measurable. The components were measured in two ways - direct and indirect measurements. The mean of total scores of the direct questionnaire indicated the score of each component. Indirect or specific factors were measured by multiplying the score of pair questionnaires to each other. The possible score was between -10 to +10 for each specific factor. Table 1 shows the questionnaire, according to the TPB component for the direct and indirect measurement.

\section{Analyses}

Prior to further analysis, a test of normality was run, and the data were normally distributed. A separate, independent sample Student's $t$-test was employed for each sex group to compare means of baseline data for sociodemographic, socioeconomic, and anthropometry between ExG and CoG. Structural equation modeling, using add-in analysis of moment structure in SPSS version 18.0 (SPSS Inc, Chicago, IL, USA), was applied to the TPB questionnaire. The model that was created provided the $\beta$-coefficient values that could then be used to determine the most specific factor to be the predictor and most influencing behavior toward exercise. The multiple regression coefficient $\left(R^{2}\right)$ from the model could also be used to investigate the maintenance of exercise of the subject along the 12-week intervention study.

\section{Results}

\section{Sociodemographic, socioeconomic, and} anthropometric characteristics of subjects

In all, 65 elderly - 34 from the ExG and 31 from the $\mathrm{CoG}$ (a response rate of $85.5 \%$ ) - successfully completed the

Table I Questionnaire of TPB for each component

\begin{tabular}{|c|c|c|}
\hline TPBs component & Question & Scoring scale \\
\hline \multirow[t]{10}{*}{ Attitude } & Direct measurement & $+I$ (not very good) to +5 (very good) \\
\hline & For me, exercise is... & $+\mathrm{I}$ (not very beneficial) to +5 (very beneficial) \\
\hline & & $+I$ (unhealthiest) to +5 (healthiest) \\
\hline & & + I (very tired) to +5 (very refreshing) \\
\hline & & + I (very unhappy) to +5 (very happy) \\
\hline & Indirect measurement (specific factor) & \\
\hline & Pain after exercise & \\
\hline & Want to be healthier & \\
\hline & Fatigue after exercise & First unipolar scale + I (disagree) to +5 (agree) \\
\hline & Not motivated to exercise & Second bipolar scale -2 (disagree) to +2 (agree) \\
\hline \multirow[t]{11}{*}{ Subjective norms } & Direct measurement & \\
\hline & People close to me think, and hope, I should participate & All measured in 5 unipolar scale, \\
\hline & in regular exercise & +I (disagree) to +5 (agree) \\
\hline & My friends think that they should influence me to & \\
\hline & perform exercise & \\
\hline & My surroundings influence me to practice exercise & \\
\hline & Indirect measurement (specific factor) & \\
\hline & Friend perception & \\
\hline & Family support & \\
\hline & Exercise with friends/accompanying person & First unipolar scale $+\mathrm{I}$ (disagree) to +5 (agree) \\
\hline & & Second bipolar scale -2 (disagree) to +2 (agree) \\
\hline \multirow[t]{9}{*}{ Perceived behavioral control } & Direct measurement & \\
\hline & For me, practicing exercise is easy & All measured in 5 unipolar scale, \\
\hline & For me, the decision to exercise is my own decision & +I (disagree) to +5 (agree) \\
\hline & I am confident that I can perform regular exercise & \\
\hline & Indirect measurement (specific factor) & \\
\hline & Health status & \\
\hline & Exercise knowledge & \\
\hline & Occupied taking care of grandchildren & First unipolar scale + I (disagree) to +5 (agree) \\
\hline & Misconception of sedentary daily activity as exercise & Second bipolar scale -2 (disagree) to +2 (agree) \\
\hline \multirow[t]{3}{*}{ Intention } & Direct measurement & \\
\hline & I will start exercising regularly by next week & All measured in 5 unipolar scale, \\
\hline & I will exercise for myself & +I (disagree) to +5 (agree) \\
\hline
\end{tabular}

Abbreviation: TPB, theory of planned behavior. 
Table 2 Demographic and economic characteristics and health status of the subjects in the study groups, according to sex (presented as $\mathrm{n}[\%]$ )

\begin{tabular}{|c|c|c|c|c|}
\hline & \multicolumn{2}{|l|}{ Men $(\mathrm{N}=47)$} & \multicolumn{2}{|l|}{ Women $(\mathrm{N}=18)$} \\
\hline & $\begin{array}{l}\text { Exercise group } \\
(n=25)\end{array}$ & $\begin{array}{l}\text { Control group } \\
(n=22)\end{array}$ & $\begin{array}{l}\text { Exercise group } \\
(n=9)\end{array}$ & $\begin{array}{l}\text { Control group } \\
(n=9)\end{array}$ \\
\hline Age, mean \pm standard deviation & $68.4 \pm 5.8$ & $66.5 \pm 4.7$ & $65.3 \pm 4.5$ & $66.9 \pm 5.8$ \\
\hline \multicolumn{5}{|l|}{ Marital status } \\
\hline Married & $24(5 I . I)$ & $21(45.7)$ & $2(11.1)$ & $4(22.2)$ \\
\hline Divorced/unmarried & $\mathrm{I}(2.1)$ & $\mathrm{I}(2 . \mathrm{I})$ & $7(38.9)$ & $5(27.8)$ \\
\hline \multicolumn{5}{|l|}{ Living arrangement } \\
\hline Alone & $25(53.2)$ & $22(46.8)$ & I (5.6) & I (5.6) \\
\hline Not alone & $0(0)$ & $0(0)$ & $8(44.4)$ & $8(44.4)$ \\
\hline \multicolumn{5}{|l|}{ Education level } \\
\hline Lower (primary and downward) & $13(27.7)$ & $14(29.8)$ & $6(33.3)$ & $5(27.8)$ \\
\hline Higher (secondary and upward) & $12(25.5)$ & $8(17.0)$ & $3(16.7)$ & $4(22.2)$ \\
\hline \multicolumn{5}{|l|}{ Working status } \\
\hline Working & $3(6.4)$ & $\mathrm{I}(2.1)$ & I (5.6) & $0(0.0)$ \\
\hline Not working & $22(46.8)$ & $21(44.7)$ & $8(44.4)$ & $9(50.0)$ \\
\hline \multicolumn{5}{|l|}{ Financial source } \\
\hline Self & $19(40.4)$ & $18(38.3)$ & $3(16.7)$ & $6(33.3)$ \\
\hline Supported & $6(12.8)$ & $4(8.5)$ & $6(33.3)$ & $3(16.7)$ \\
\hline \multicolumn{5}{|l|}{ Smoking status } \\
\hline Smoking & $19(40.4)$ & $16(34.0)$ & $9(50.0)$ & $8(44.4)$ \\
\hline Nonsmoking & $6(12.8)$ & $6(12.8)$ & $0(0.0)$ & I (5.6) \\
\hline \multicolumn{5}{|l|}{ Diabetes patient } \\
\hline Yes & $18(38.3)$ & 15 (31.9) & $7(38.9)$ & $8(44.4)$ \\
\hline No & $7(14.9)$ & $7(14.9)$ & $2(11.1)$ & I (5.6) \\
\hline \multicolumn{5}{|l|}{ Hypertension patient } \\
\hline Yes & $16(34.0)$ & $10(21.3)$ & $5(27.8)$ & $5(27.8)$ \\
\hline No & $9(19.1)$ & $12(25.5)$ & $4(22.2)$ & $4(22.2)$ \\
\hline \multicolumn{5}{|l|}{ Asthma patient } \\
\hline Yes & $23(48.9)$ & $19(40.4)$ & $0(0.0)$ & $0(0.0)$ \\
\hline No & $2(4.3)$ & $3(6.4)$ & $9(50.0)$ & $9(50.0)$ \\
\hline \multicolumn{5}{|l|}{ Musculoskeletal problem } \\
\hline Yes & $20(42.6)^{*}$ & $10(2 \mid .3)$ & $5(27.8)$ & $4(22.2)$ \\
\hline No & $5(10.6)$ & $12(25.5)$ & $4(22.2)$ & $5(27.8)$ \\
\hline
\end{tabular}

Notes: $* P<0.05$. Significant difference for chi-square test between groups in each sex.

12-week program. Data on sociodemographic, economic, and anthropometry is shown in Table 2. The majority of male subjects in ExG had musculoskeletal problems as compared to CoG $(P<0.05)$. Nevertheless, subjects were comparable with respect to demographic data, socioeconomic status, and health characteristics.

There were no significant differences in all the anthropometric characteristics between ExG and CoG, according to sex, as shown in Table 3. Thus, subjects were homogeneous in anthropometric and health profile characteristics. After 12 weeks of intervention, most variables measured did not show any significant changes. However, weight and body mass index showed a nearly significant value with large effect size $\left(\eta p^{2}>0.14\right)$. Large effect size indicates that there was a possibility that significant changes would be observed if the sample size increased (data not shown).

\section{Contribution of factor and TPB components toward exercise according to sex}

As shown in Figure 3, attitude (standardized coefficients $=0.60$ ) was the most important component for predicting intention to exercise, followed by perceived behavioral control (standardized coefficients $=0.24$ ) among men at the baseline. Subjective norm (standardized coefficients $=0.02$ ) had a weak impact on the intention to exercise. All of these three components contributed up to $41 \%$ of the intention to perform the exercise at baseline. "Not motivated to exercise" (standardized coefficients $=-0.36$ ) was the specific factor within the attitude component that negatively influenced the intention to engage in exercise among men.

Figure 4 shows that three components were observed to be important predictors of intention to perform the exercise among women: subjective norm (standardized 
Table 3 Anthropometry and physical characteristic of subjects in the study groups, according to sex

\begin{tabular}{|c|c|c|c|c|}
\hline & \multicolumn{2}{|l|}{ Men $(\mathrm{N}=47)$} & \multicolumn{2}{|c|}{ Women $(\mathrm{N}=18)$} \\
\hline & $\begin{array}{l}\text { ExG } \\
(n=25)\end{array}$ & $\begin{array}{l}\text { CoG } \\
(n=22)\end{array}$ & $\begin{array}{l}\text { ExG } \\
(n=9)\end{array}$ & $\begin{array}{l}\text { CoG } \\
(n=9)\end{array}$ \\
\hline Weight (kg) & $64.5 \pm 9.1$ & $67.7 \pm 11.7$ & $55.6 \pm 15.8$ & $56.5 \pm 11.3$ \\
\hline Height (cm) & $161.8 \pm 7.2$ & $162.3 \pm 5.6$ & $148.4 \pm 2.9$ & $150.3 \pm 5.1$ \\
\hline BMI $\left(\mathrm{kg} / \mathrm{m}^{2}\right)$ & $24.9 \pm 3.2$ & $25.5 \pm 3.4$ & $25.1 \pm 6.6$ & $24.9 \pm 4.1$ \\
\hline Handgrip strength (kg) & $45.8 \pm 12.4$ & $48.6 \pm 14.5$ & $29.6 \pm 9.4$ & $23.8 \pm 4.7$ \\
\hline Waist circumference & $89.3 \pm 11.0$ & $83.2 \pm 14.3$ & $89.9 \pm 11.1$ & $87.0 \pm 18.0$ \\
\hline Mid upper arm circumference & $30.0 \pm 3.4$ & $27.9 \pm 5.9$ & $29.0 \pm 2.5$ & $29.9 \pm 4.7$ \\
\hline Total MET & $1,520.8 \pm 943.9$ & $\mathrm{I}, 622.0 \pm \mathrm{I}, 095.0$ & $1,057.2 \pm 603.6$ & $|, 503.1 \pm 39| .8$ \\
\hline
\end{tabular}

Note: Values presented as mean \pm standard deviation.

Abbreviations: ExG, exercise group; CoG, control group; BMI, body mass index; MET, metabolic equivalent.

coefficients $=0.82$ ); perceived behavioral control (standardized coefficients $=0.34$ ); and attitude (standardized coefficients $=0.24$ ). These three components contributed $85 \%$ of the women's intention to perform the exercise at the baseline. Together with perceived behavioral control, intention contributed $48 \%$ to the actual behavior. Figure 5 also indicates that "want to be healthier" ( standardized coefficients $=0.80$ ), "family support" (standardized coefficients $=0.74$ ), and "friends' perception" (standardized coefficients $=0.58$ ) were the most positive influence of exercise behavior in women. However, "occupied taking care of grandchildren" (standardized coefficients $=-0.64$ ) was the most specific factor that negatively influenced the intention of elderly women to perform the exercise.

\section{Contribution of factors and TPB components toward exercise according to study group}

As shown in Figure 5, attitude (standardized coefficients $=0.69$ ) was the important predictor of intention to perform the exercise, followed by subjective norm (standardized coefficients $=0.31$ ), and perceived behavioral control (standardized coefficients $=0.22$ ) among ExG at baseline. "Occupied taking care of grandchildren" (standardized coefficients $=-0.46$ ) was found as a very important obstacle or barrier to ExG subjects to performing exercise.

However, "occupied taking care of grandchildren" (standardized coefficients $=-0.28$ ) became less important during the 12-week exercise intervention (Figure 6). "Want

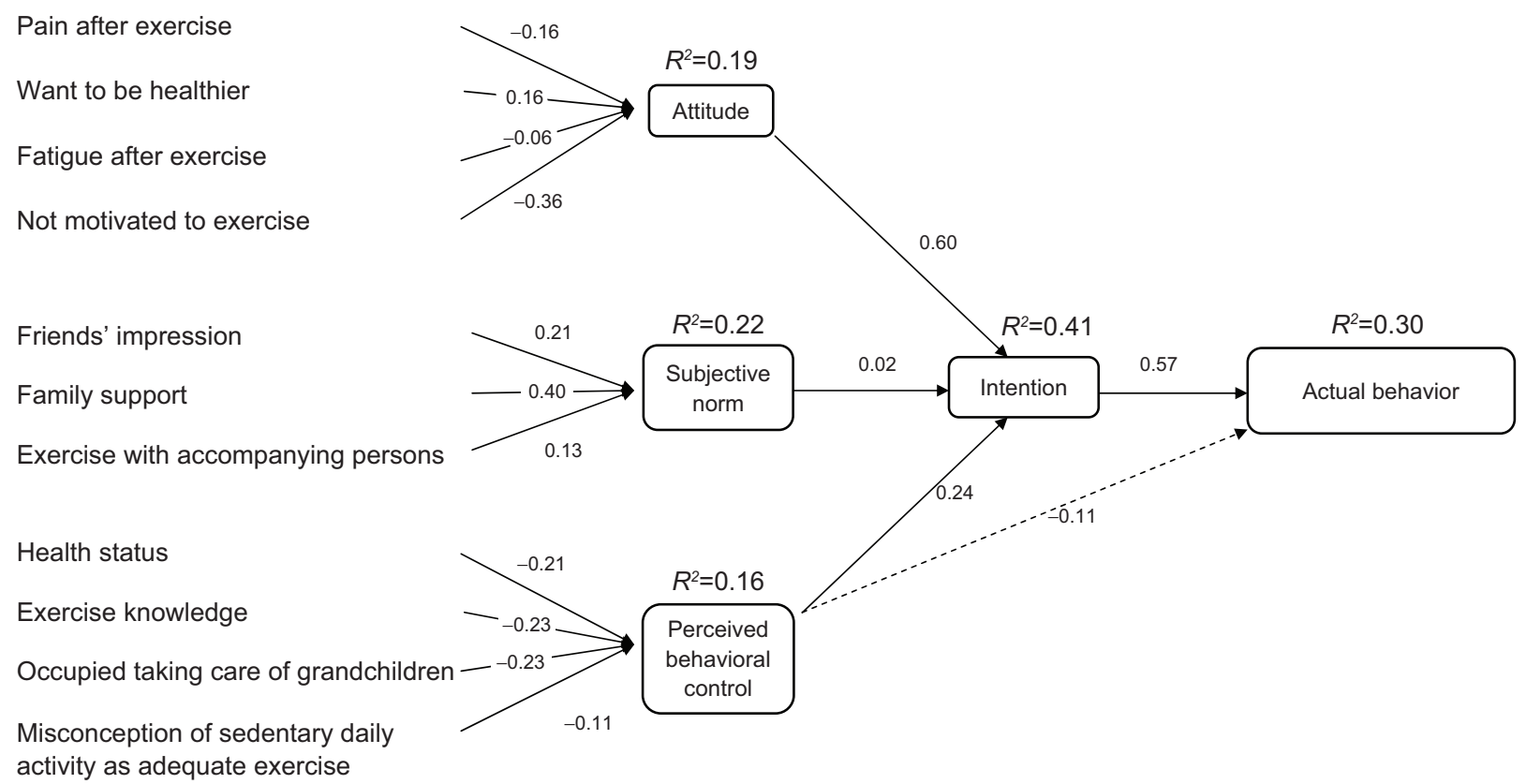

Figure 3 SEM of behavior toward exercise among men subjects at baseline. Abbreviation: SEM, structural equation modeling. 
Pain after exercise

Want to be healthier

Fatigue after exercise

Not motivated to exercise
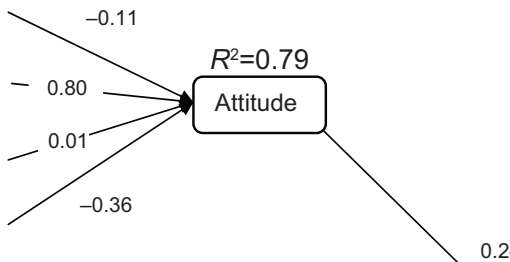

Friends impression

Family support

Exercise with accompanying persons

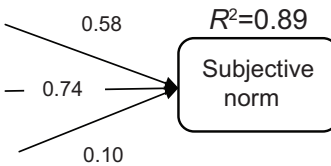

.89

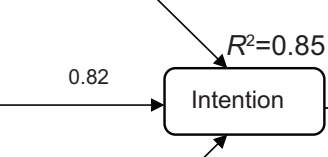

$R^{2}=0.48$

Health status

Exercise knowledge

Occupied taking care of grandchildren

Misconception of sedentary daily

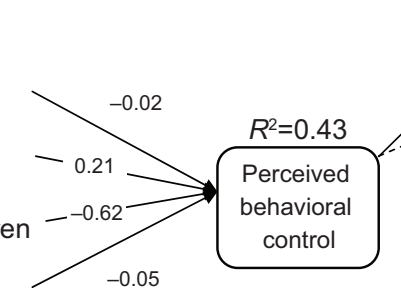

activityas an adequate exercise

Figure 4 SEM of behavior toward exercise among women subjects at baseline.

Abbreviation: SEM, structural equation modeling.

to be healthier" was the most important predictor to initiate exercise behavior for subjects in this group at baseline (standardized coefficients $=0.80$ ) and 12 weeks of intervention (standardized coefficients $=0.49$ ). The contribution of TPB components to intention decreased from $63 \%$ at baseline to $47 \%$ at 12 weeks of intervention study. However, contribution of intention and perceived behavioral control component toward the actual behavior of exercise was incrementally small: $43 \%$ at baseline to $44 \%$ at 12 weeks.

Among $\mathrm{CoG}$, attitude (standardized coefficients $=0.45$ ) was the most important component contributing to intention to perform the exercise at the baseline as they perceived

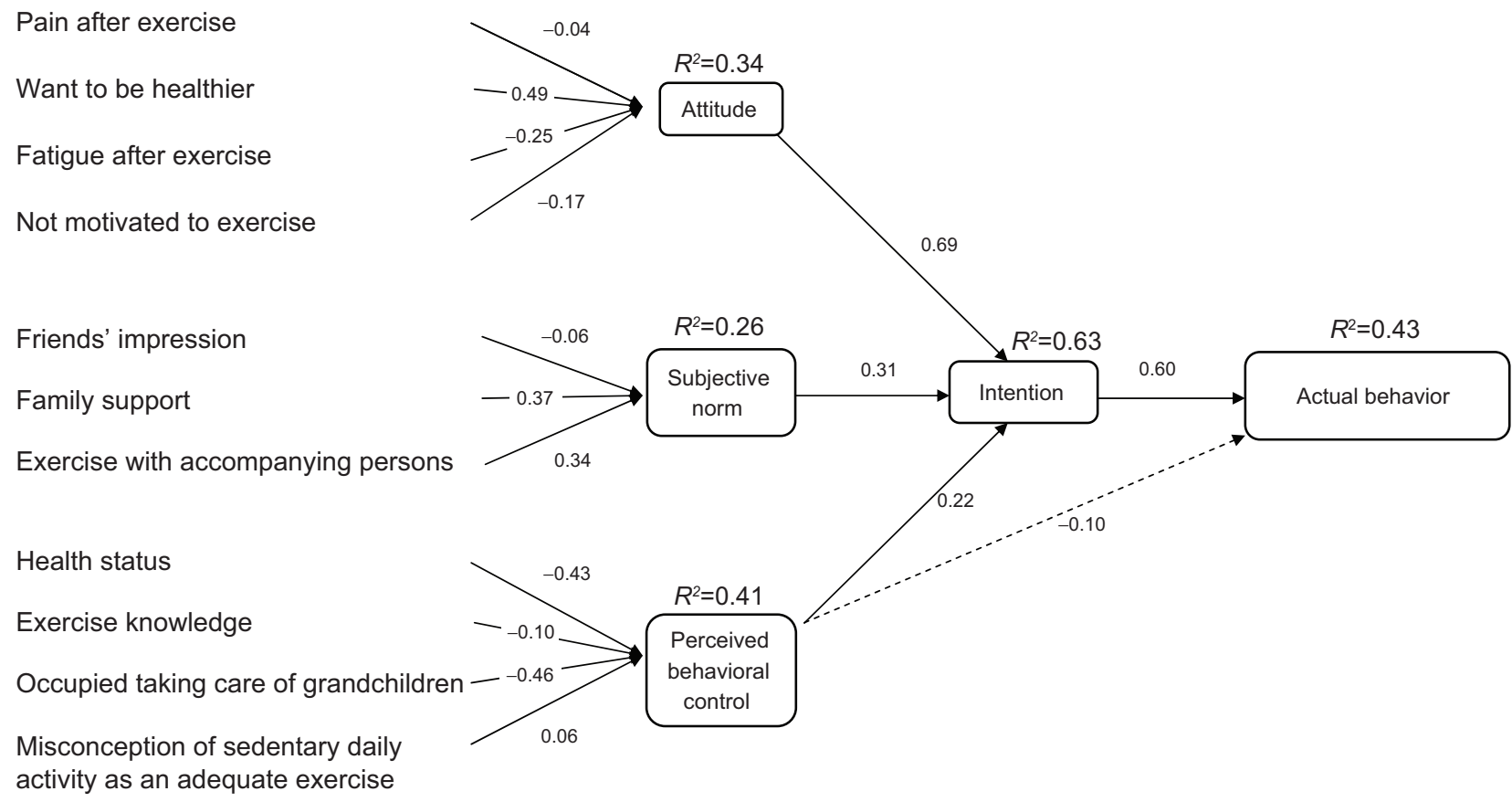

Figure 5 SEM of behavior toward exercise among ExG at baseline.

Abbreviations: SEM, structural equation modeling; ExG, exercise group. 


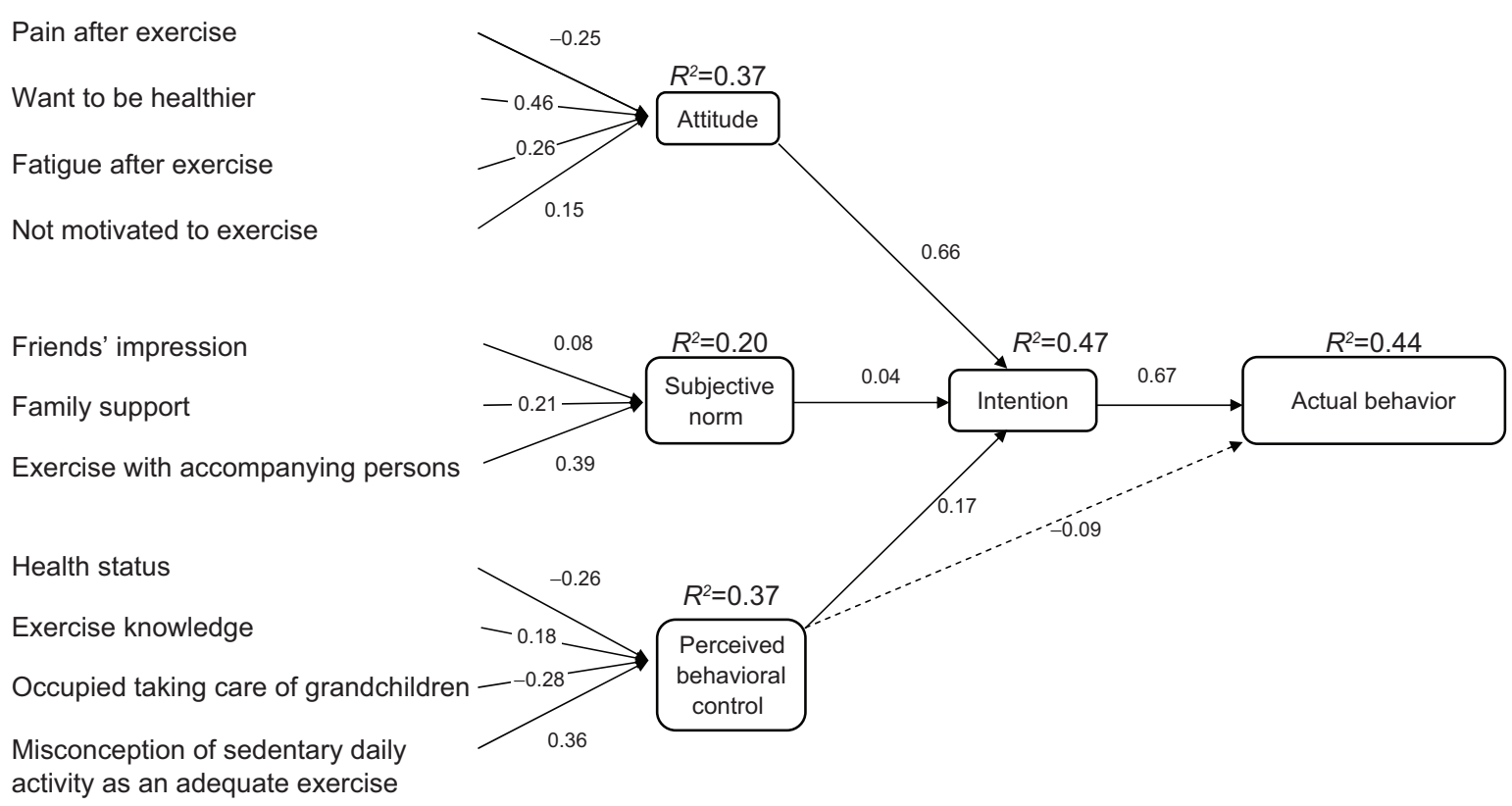

Figure 6 SEM of behavior toward exercise among ExG at 12 weeks.

Abbreviations: SEM, structural equation modeling; ExG, exercise group.

that exercise was important if they wanted to be healthier ( standardized coefficients $=0.63$ ). However, family support (standardized coefficients $=0.43$ ) was an important specific factor for $\mathrm{CoG}$ subjects. The contribution of subjective norm ( standardized coefficients $=0.10$ ) to the intention was the smallest as compared to the attitude and perceived behavioral control as shown in Figure 7.
As shown in Figure 8, at 12 weeks of intervention, it was found that friend perception (standardized coefficients $=0.33$ ) negatively influenced exercise behavior among subjects in the $\mathrm{CoG}$, although they had good family support ( standardized coefficients $=0.36$ ). Both specific factors were important contributors to the subjective norm component (standardized coefficients $=0.72$ ), which was the strongest

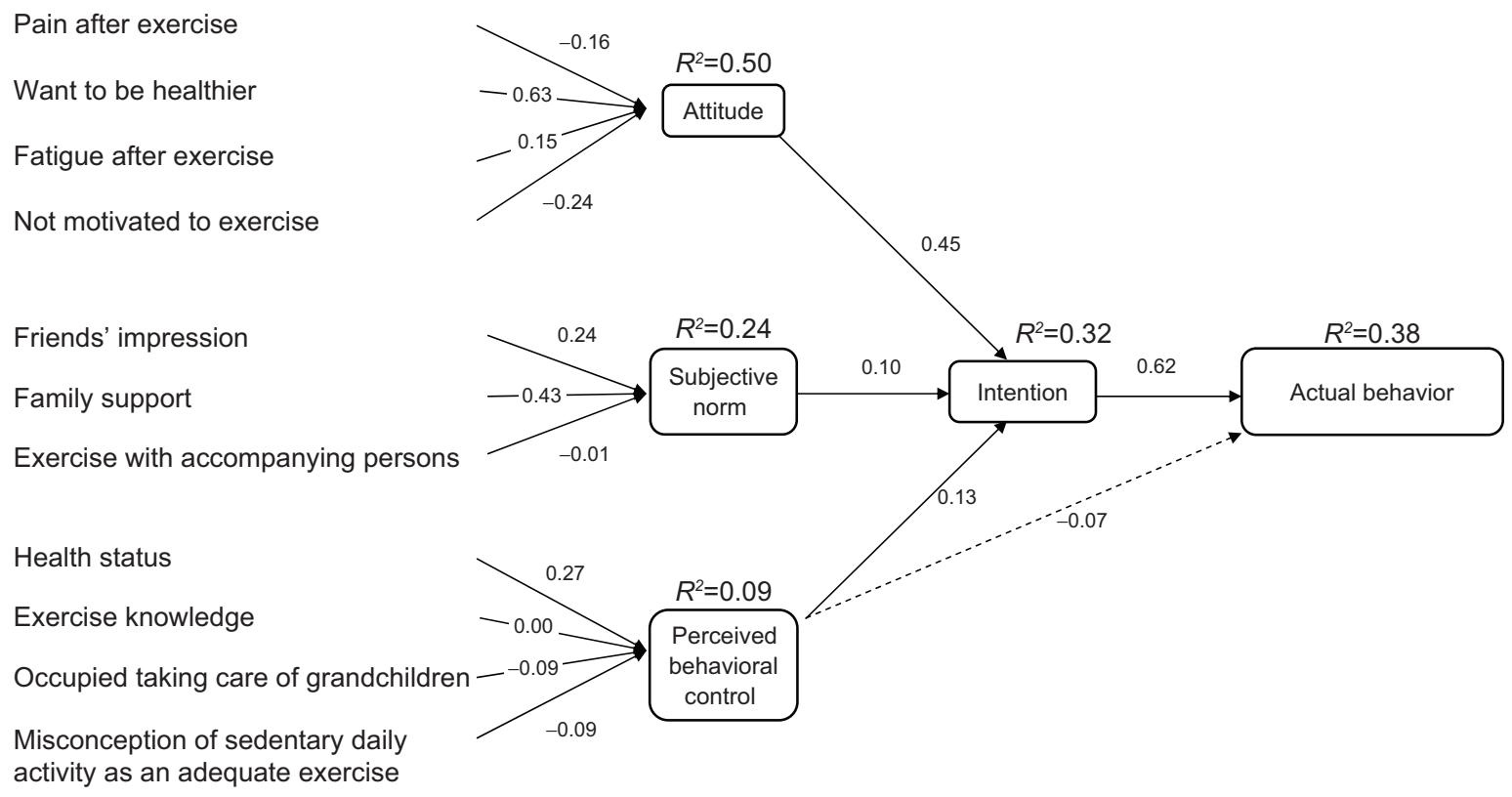

Figure 7 SEM of behavior toward exercise among CoG at baseline. Abbreviations: SEM, structural equation modeling; CoG, control group. 


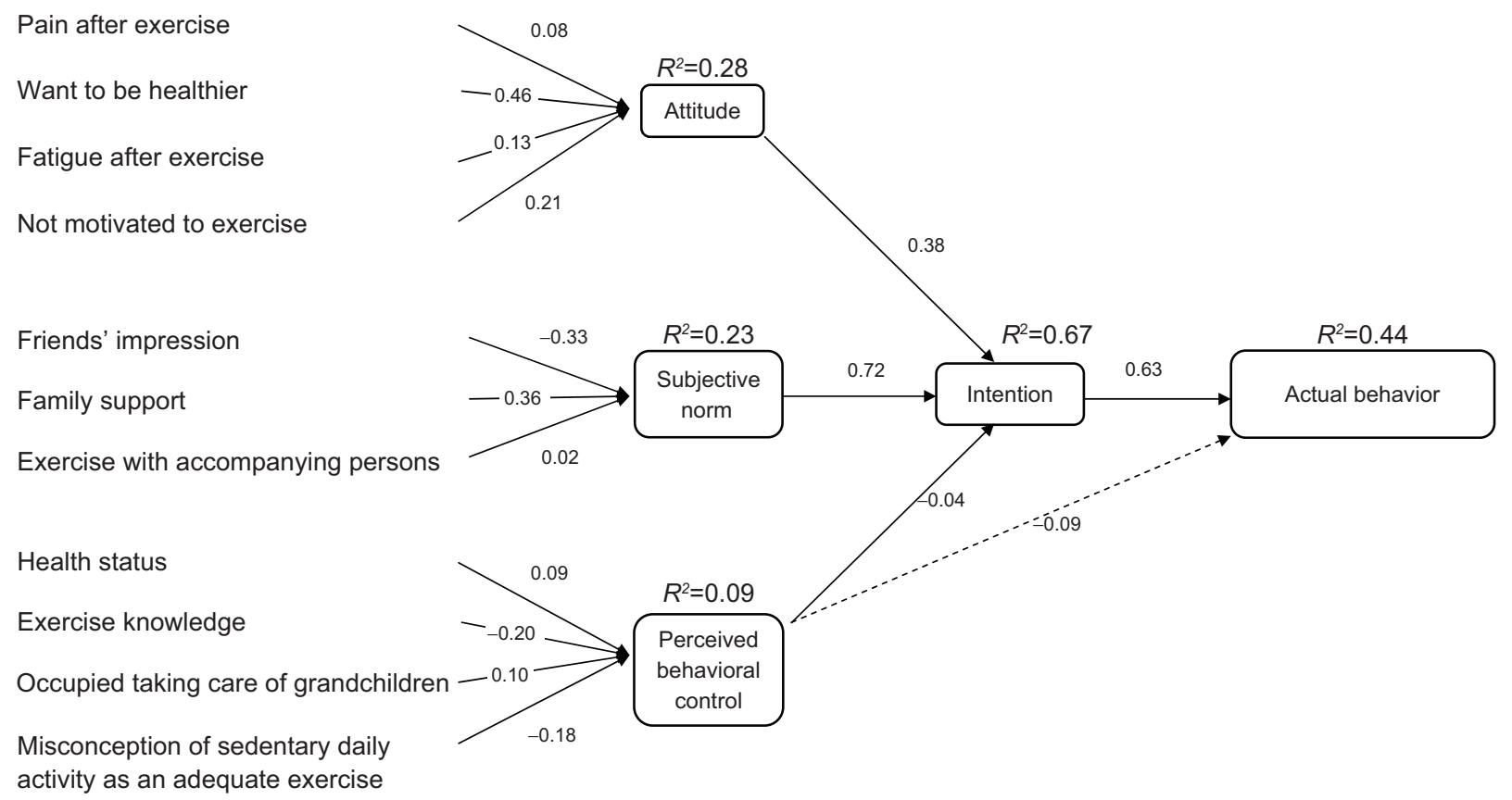

Figure 8 SEM of behavior toward exercise among CoG at 12 weeks. Abbreviations: SEM, structural equation modeling; CoG, control group.

predictor to intention toward exercise behavior among $\mathrm{CoG}$ at 12 weeks. The contribution of these three TPB components toward intention had increased from $32 \%$ at baseline to $67 \%$ after a 12 -week period. Together with perceived behavioral control, intention contributed $33 \%$ of actual behavior at baseline and $44 \%$ at 12 weeks.

\section{Discussion}

Generally, subjects' characteristics on demography, economic, anthropometry, and health status at baseline were similar between ExG and $\mathrm{CoG}$ in both sexes, except for the presence of musculoskeletal problems in men subjects. A musculoskeletal problem is a common, frequently under reported, and inadequately treated condition in the older adult. ${ }^{18}$ However, musculoskeletal problems that were reported in this study only refer to mild musculoskeletal problems and the affected subjects were still willing and believed that they could exercise. Much evidence supports the effectiveness of physical therapy, such as exercise and resistance training, in treating musculoskeletal pain among older adults. ${ }^{19,20}$ Qualitative data from our FGD also revealed that "feel want to be healthier" was one of the factors influencing subjects to perform the exercise. Previous studies also reported that the main reason for most senior citizens engaging in exercise was to maintain their health. ${ }^{21,22}$

Most elderly people have a misconception regarding physical activity and exercise especially in CoG, which may indirectly make them be physically inactive. Some of the elderly individuals had the perception that exercise was not suitable for them anymore and the daily activity that they were doing was enough to be considered exercise. ${ }^{23} \mathrm{~A}$ general misconception of modern culture is to accept that old age is a time for relaxation and that physical activity and exercise are unnecessary or even harmful. ${ }^{24}$ The misconception toward exercise exposes them to various health problems and diseases. $^{25}$

In the present study, we found that intention to perform the exercise was influenced by the attitude component at the baseline and after 12 weeks of intervention study in both ExG and CoG. Attitude was a key component influencing exercise behavior. ${ }^{26}$ However, specific factors influencing the exercise are different between populations and areas. ${ }^{27}$ During the initial phase of this study, "not motivated to exercise," was the major obstacle among men and "occupied taking care of grandchildren" was the specific factor negatively affecting the intention to exercise among women. A study conducted among Iranians also found that the majority of the Iranian elderly did not practice exercise because of their lazy attitude. ${ }^{28}$

Studies conducted among the elderly in Canada found that all three TPB components had significant correlation with the intention to exercise. ${ }^{29}$ These findings were similar to ours with respect to the women, of which attitudes, subjective norms, and perceived behavioral control all contributed to the intention to perform the exercise. In this study, 
encouragement of the family was a specific factor in the subjective norm component that influenced older women to perform the exercise. For women, family was more important than their friends were, but not for men. Women in particular were more likely to be confined at home doing activities with their families than older men. ${ }^{30,31}$ In addition, minding the grandchildren was found to be a major obstacle within the perceived behavioral controls that restricted the exercise behavior of women. These internal and external factors might be the possible explanation of why older women were less active than men, although they were willing to perform the exercises. $^{32}$

"Occupied in taking care of grandchildren" was a negatively influenced intention of exercise in ExG and CoG at baseline. However, in this study, subjects were given an elastic band (TheraBand) as a tool to perform the exercise, and this exercise was easy to perform, even while looking after their grandchildren. Therefore, at 12 weeks of intervention, the influence of this factor decreased in both study groups. Simple, easy, and suitable tools or equipment for exercise are important in encouraging exercise among the elderly since most of them are no longer able to do heavy exercise due to various limitations. ${ }^{33}$

When the prediction and maintenance of exercise between ExG and CoG were compared, both groups showed an increasing trend in the intention and perceived behavioral control toward the actual behavior of exercise. However, the contribution of subjective norm components toward intention obviously increased in CoG at 12 weeks. Family support and friend perception were the main factors influencing the $\mathrm{CoG}$ subjects with respect to the intention to perform the exercise. However, the contribution was only $23 \%$ to the intention to perform the exercise.

Based on our data, we believe that the reduction in the intention to perform the exercise in the ExG was due to the subjective norm component. Even though they had performed exercise with their peers, they still had some thoughts that their friends had wrong perceptions of what they were doing. Family support also reduced in ExG throughout the intervention program. Support from family members and important persons, such as best friends, was a significant factor for the elderly for exercising regularly. ${ }^{34,35}$

This study has several limitations. First, no randomization in subject selection might be a limitation. Second, the samples for the present study were small, and there was disparity in the number of men and women. Third, the subjects were mostly Malays who were recruited at a low-income residential area in the suburban areas of Kuala Lumpur.
Thus, the results of the study cannot be generalized with others. A future study should consider randomization and include other ethnicities, cultures, and geographical locations as well. Nevertheless, the study has highlighted the usefulness of TPB in understanding a behavior change among elderly individuals that can also be applied to determining other health behaviors. Such information is vital in providing a more tailored intervention.

\section{Conclusion}

In conclusion, the present study found that - through the application of TPB - participation of subjects in doing exercise was mostly influenced by attitude among men and subjective norm among women. "Not motivated to perform exercise" was a specific factor that affected attitude toward exercise in men; meanwhile, family and friends were the important supporters to engage exercise among women. An understanding of these motivational forces and barriers is invaluable in the planning and implementation of effective strategies and intervention programs to gain good compliance toward exercise among elderly individuals. There is a need to find ways to motivate the elderly and to get the involvement of their families and friends to encourage them to perform exercise regularly.

\section{Disclosure}

The authors report no conflicts of interest in this work.

\section{References}

1. Bandura A, Adams NE, Beyer J. Cognitive processes mediating behavioral change. J Pers Soc Psychol. 1977;35(3):125-139.

2. Cowan PA, Langer J, Heavenrich J, Nathanson M. Social learning and Piaget's cognitive theory of moral development. J Pers Soc Psychol. 1969;11(3):261-274.

3. Fishbein M. A theory of reasoned action: some applications and implications. Nebr Symp Motiv. 1980;27:65-116.

4. Secord PF, Backman CW. Personality theory and the problem of stability and change in individual behavior: an interpersonal approach. Psychol Rev. 1961;68:21-32.

5. Schifter DE, Ajzen I. Intention, perceived control, and weight loss: an application of the theory of planned behavior. J Pers Soc Psychol. 1985;49(3):843-851.

6. France JL, France CR, Himawan LK. A path analysis of intention to redonate among experienced blood donors: an extension of the theory of planned behavior. Transfusion. 2007;47(6):1006-1013.

7. Ajzen I. The theory of planned behaviour: reactions and reflections. Psychol Health. 2011;26(9):1113-1127.

8. Rise J, Thompson M, Verplanken B. Measuring implementation intentions in the context of the theory of planned behavior. Scand J Psychol. 2003;44(2):87-95.

9. Clayton DA, Griffith CJ. Efficacy of an extended theory of planned behaviour model for predicting caterers' hand hygiene practices. Int J Environ Health Res. 2008;18(2):83-98.

10. Garland T Jr, Schutz H, Chappell MA, et al. The biological control of voluntary exercise, spontaneous physical activity and daily energy expenditure in relation to obesity: human and rodent perspectives. J Exp Biol. 2011;214(Pt 2):206-229. 
11. Lee IM, Shiroma EJ, Lobelo F, Puska P, Blair SN, Katzmarzyk PT; Lancet Physical Activity Series Working Group. Effect of physical inactivity on major non-communicable diseases worldwide: an analysis of burden of disease and life expectancy. Lancet. 2012;380(9838):219-229.

12. Cruz-Jentoft AJ, Baeyens JP, Bauer JM, et al; European Working Group on Sarcopenia in Older People. Sarcopenia: European consensus on definition and diagnosis: Report of the European Working Group on Sarcopenia in Older People. Age Ageing. 2010;39(4): 412-423.

13. Janssen I, Heymsfield SB, Ross R. Low relative skeletal muscle mass (sarcopenia) in older persons is associated with functional impairment and physical disability. J Am Geriatr Soc. 2002;50(5):889-896.

14. Lima RM, Bezerra LM, Rabelo HT, et al. Fat-free mass, strength, and sarcopenia are related to bone mineral density in older women. J Clin Densitom. 2009;12(1):35-41.

15. Borst SE. Interventions for sarcopenia and muscle weakness in older people. Age Ageing. 2004;33(6):548-555.

16. Lang T, Streeper T, Cawthon P, Baldwin K, Taaffe DR, Harris TB. Sarcopenia: etiology, clinical consequences, intervention, and assessment. Osteoporos Int. 2010;21(4):543-559.

17. Avers D, Brown M. White paper: Strength training for the older adult. J Geriatr Phys Ther. 2009;32(4):148-152, 158.

18. Taaffe DR, Marcus R. 2000. Musculoskeletal health and the older adult. J Rehabil Res Dev. 2000;37(2):245-254.

19. Johnston AP, De Lisio M, Parise G. Resistance training, sarcopenia, and the mitochondrial theory of aging. Appl Physiol Nutr Metab. 2008; 33(1):191-199.

20. Winett RA, Williams DM, Davy BM. Initiating and maintaining resistance training in older adults: a social cognitive theory-based approach. Br J Sports Med. 2009;43(2):114-119.

21. O'Donovan G, Blazevich AJ, Boreham C, et al. The ABC of Physical Activity for Health: a consensus statement from the British Association of Sport and Exercise Sciences. J Sports Sci. 2010;28(6): 573-591.

22. Foley A, Hillier S, Barnard R. 2011. Effectiveness of once-weekly gym-based exercise programmes for older adults post discharge from day rehabilitation: a randomised controlled trial. $\mathrm{Br} J$ Sports Med. 2011;45(12):978-986.

23. Grove NC, Spier BE. Motivating the well elderly to exercise. J Community Health Nurs. 1999;16(3):179-189.
24. Buttery AK, Martin FC. Knowledge, attitudes and intentions about participation in physical activity of older post-acute hospital inpatients. Physiotherapy. 2009;95(3):192-198.

25. Waters DL, Baumgartner RN, Garry PJ, Vellas B. Advantages of dietary, exercise-related, and therapeutic interventions to prevent and treat sarcopenia in adult patients: an update. Clin Interv Aging. 2010;5:259-270

26. Ghahremani L, Niknami S, Nazari M. The prediction of physical activity intention and behavior in elderly male residents of a nursing home: a comparison of two behavioral theories. Iran J Med Sci. 2012;37(1):23-31

27. Sohng KY, Moon JS, Song HH, Lee KS, Kim YS. Fall prevention exercise program for fall risk factor reduction of the communitydwelling elderly in Korea. Yonsei Med J. 2003;44(5):883-891.

28. Mortazavi SS, Mohammad K, Ardebili HE, Beni RD, Mahmoodi M, Keshteli AH. 2012. Mental disorder prevention and physical activity in Iranian elderly. Int J Prev Med. 2012;3(Suppl 1):S64-S72.

29. Courneya KS. Understanding readiness for regular physical activity in older individuals: an application of the theory of planned behavior. Health Psychol. 1995;14(1):80-87.

30. Fredman L, Bertrand RM, Martire LM, Hochberg M, Harris EL. Leisure-time exercise and overall physical activity in older women caregivers and non-caregivers from the Caregiver-SOF Study. Prev Med. 2006;43(3):226-229.

31. Dafna M, Carmen C, Kamalesh V, Adrian B. How diverse was the leisure time physical activity of older Australians over the past decade? J Sci Med Sport. 2012;15(3):213-219.

32. Ura C, Taga T, Yamazaki S, Yatomi N. [The factors influencing motivation to start exercise among elderly people in an urban area]. Nihon Ronen Igakkai Zasshi. 2011;48(4):345-351. Japanese [with English abstract].

33. Tager IB, Haight T, Sternfeld B, Yu Z, van Der Laan M. Effects of physical activity and body composition on functional limitation in the elderly: application of the marginal structural model. Epidemiology. 2004;15(4):479-493.

34. Booth ML, Owen N, Bauman A, Clavisi O, Leslie E. Social-cognitive and perceived environment influences associated with physical activity in older Australians. Prev Med. 2000;31(1):15-22.

35. Kimura M, Moriyasu A, Kumagai S, et al. Community-based intervention to improve dietary habits and promote physical activity among older adults: a cluster randomized trial. BMC Geriatr. 2013;13:8.
Clinical Interventions in Aging

\section{Publish your work in this journal}

Clinical Interventions in Aging is an international, peer-reviewed journal focusing on evidence-based reports on the value or lack thereof of treatments intended to prevent or delay the onset of maladaptive correlates of aging in human beings. This journal is indexed on PubMed Central, MedLine,

\section{Dovepress}

CAS, Scopus and the Elsevier Bibliographic databases. The manuscript management system is completely online and includes a very quick and fair peer-review system, which is all easy to use. Visit http://www.dovepress. com/testimonials.php to read real quotes from published authors. 